\title{
Competitive Adsorption of Heavy Metals Copper, Cadmium and Lead by Synthetic Zeolite
}

\author{
Xiao ZHANG \\ Jiangsu City Vocational College \\ Nanjing 210036, China
}

\section{Chen CHEN* $^{*}$}

School of Environmental and Chemical Engineering

Jiangsu University of Science and Technology

Zhenjiang 212003, China

e-mail: chenc@just.edu.cn

\author{
Ting CHENG \\ Jiangsu City Vocational College \\ Nanjing 210036, China \\ e-mail: wnchengting@sina.com
}

\begin{abstract}
The experiments are to study the competitive adsorption properties of three heavy metals of $\mathrm{Cu}^{2+}, \mathrm{Cd}^{2+}$ and $\mathbf{P b}^{2+}$ ions through synthesizing zeolite. The influencing factors and competitive adsorption kinetic modes are investigated. The results show that, with the increase of adsorbed dose, the removal rate of zeolite on the adsorption of three heavy metals all rise constantly, and the saturated adsorption capacity all drops gradually. When the value of initial concentration are 50 and $100 \mathrm{mg} / \mathrm{L}$, the competitive adsorption sequence of zeolite on three heavy metal ions is: $\mathrm{Pb}>\mathrm{Cu}>\mathrm{Cd}$. The removal rate of zeolite on the adsorption of three heavy metal ions all increases with the rise of the value of initial $\mathrm{pH}$ on the whole. During the competitive adsorption process, at various value of initial $\mathrm{pH}$ and concentration, the adsorption sequence of zeolite on three heavy metals remains still: $\mathrm{Pb}>\mathrm{Cu}>\mathrm{Cd}$. The reaction time has an apparent effect on the removal rate of three heavy metals ions. The removal rate of zeolite increases gradually with the increase of reaction time, and the adsorption removal rate improves quickly within 2 hours. The value of equilibrium adsorption capacity of quasi second-class kinetic equation $\mathbf{Q}_{\exp }$ is closer to the value of equilibrium adsorption capacity $Q_{\text {cal }}$ according to experimental measurement. The adsorption behavior of synthetic zeolite materials on the adsorption of three heavy metal ions all fits for quasi second-class adsorption kinetic equation.
\end{abstract}

Keywords-Heavy metal, Copper, Cadmium, Lead, Fly ash, zeolite, Competitive adsorption

\section{INTRODUCTION}

With the rapid development of mining, smelting, chemical engineering, electroplating, electronics, leather and so on, the accidental emissions of heavy metal pollutions and the usage of too much fertilizer and pesticide make different kinds of heavy metal pollutions poured into the water [1-3]. The Lead pollution can not only affect human health, but also the growth of children's intelligence [1]. Cadmium is an extremely poisonous oxide and will accumulate in plants, animals and the inner side of human body. Besides, it is harmful to the health of plants and animals and human beings [4]. The heavy metal such as lead and cadmium and its compounds have been listed as priority-control pollutants by the State Environmental Protection Administration of China. If the skin isexposed to the compounds of heavy metal copper,the skin would necrosis at high concentration. The treatment of heavy metal pollution in the water has become one of the problems widely concerned at home and abroad [5-7].

The treatments of heavy metal wastewater can be divided into two classes: one kind is to transform the resolvable heavy metal into the metal compounds that are unable or hard to dissolve so that it can be removed from the water, such as oxidation reduction, chemical precipitation, etc. The other one is conducting concentration and separation under the circumstance that the chemical form of heavy metals remain still, such as adsorption, reverse osmosis, ion exchange and so on. There are some other treatment methods such as air flotation, membrane separation and solution extraction and so on. In recent years, the research of the treatment of heavy metal wastewater by using new adsorbent has been widely focused, depending on the adsorption effect of active surface of adsorbent on heavy metal ions [3-5]. The essence of adsorption is the choice of adsorbents. There is too much research, which is the adsorption treatment on heavy metal wastewater by adsorbent and the research exploitation of economic, effective and easily-accessible adsorption materials has been hot spot.

Fly ash is one kind of clay-like volcanic material emitted from coal combustion. Fly ash contains porous vitreous body and carbon particle and honeycomb structure with large specific surface area. Besides, it contains active groups and extremely active adsorption properties. In recent years, the research of the removal of heavy metal in the water by using fly ash as adsorbent has been widely concerned[8,9]. Some industrial wastewater that contains toxic substances and industrial wastewater such as $\mathrm{Cr}^{3+}, \mathrm{Hg}^{2+}, \mathrm{Pb}^{2+}, \mathrm{F}^{-}$and phenols can be handled by fly ash. However, the adsorption effect in original state is not very satisfying.

Currently, the research about using fly ash to realize the synthesis of zeolite or some other adsorbent combinations to improve the adsorption ability of fly ash has broader 
prospects[3,10]. There are a lot of equal holes and channels in the inner side of zeolite crystal, which make the zeolite a high specific surface area. The research indicates that the materials synthesized by using fly ash have excellent ability to remove the heavy metal ions in the water. However, currently, the majority of the research concentrates on adsorption properties of single heavy metal ions. But the research on the competitive adsorption of multiple heavy metal ions is not comprehensive enough.

This research uses fly ash as the basic material to realize the synthesis of zeolite adsorbent and studies its competitive adsorption effect on $\mathrm{Pb}^{2+}, \mathrm{Cd}^{2+}, \mathrm{Cu}^{2+}$ and adsorption mechanism. Study the adsorbed dose,the value of $\mathrm{pH}$ and the reaction time on the competitive adsorption of zeolite material about three heavy metals; then study the kinetic model of competitive adsorption of zeolite materials on $\mathrm{Pb}^{2+}, \mathrm{Cd}^{2+}, \mathrm{Cu}^{2+}$ on such basis. We look forward to obtaining highly effective heavy metal adsorption materials. In the meantime, we use wastes to deal with the wastes and turn the wastes into valuable substances so that we can provide technical references for the treatment technology of heavy metal wastewater.

\section{EXPERIMENTAL}

The experimental synthetic zeolite materials use fly ash as the raw material, the main chemical components of samples are: the mass fraction of silicon dioxide,lead dioxide,iron sesquioxide,calcium oxide,titanium oxide and magnesium oxide are 50.01\%,33.45\%,4.71\%,2.87\%,1.09\% and $0.87 \%$ respectively. The $\mathrm{Cu}^{2+}$ aqueous solution, the $\mathrm{Cd}^{2+}$ aqueous solution and the $\mathrm{Pb}^{2+}$ aqueous solution is prepared through dissolving $\mathrm{Cu}\left(\mathrm{NO}_{3}\right)_{2} \cdot 3 \mathrm{H}_{2} \mathrm{O}, \mathrm{Cd}\left(\mathrm{NO}_{3}\right)_{2}$ and $\mathrm{Pb}\left(\mathrm{NO}_{3}\right)_{2}$ in DI water, respectively. All chemicals used in our experiment are analytical reagent and bought from China National Pharmaceutical Group Corporation.

The preparation for zeolite materials. The preparation process of zeolite materials is: put fly ash that weighs 2 gram into potassium Sodium hydroxide solution whose volume is $50 \mathrm{ml}$ and concentration is $8 \mathrm{~mol} / \mathrm{L}$, keep reacting for 48 hours under the condition of $95^{\circ} \mathrm{C}$. After finishing it, use deionized water to wash the obtained materials until it is neutral and dry it to the constant weight in the bake oven whose temperature is $105^{\circ} \mathrm{C}$. After the synthetic reaction is done, the samples are identified by XRD and SEM, which makes sure that it is zeolite material.

The batch studies are conducted by mixing zeolite with $\mathrm{Cu}^{2+}, \mathrm{Cd}^{2+}$ and $\mathrm{Pb}^{2+}$ metallic solutions prepared in the laboratory. The zeolite is mixed with heavy metal ions in 10 $\mathrm{ml}$ polypropylene tubes. The $\mathrm{pH}$ of solution is adjusted by $0.01 \mathrm{~mol} / \mathrm{L} \mathrm{NaOH}$ and $0.01 \mathrm{~mol} / \mathrm{L} \mathrm{HNO}_{3}$ solutions. The tubes with mixtures are fixed in a water bath shaking box and shaken at $120 \mathrm{rpm}$. The mixture is filtered through $0.45 \mu \mathrm{m}$ membrane filter using a vacuum pump after adsorption reaction. The filtrate is analyzed subsequently for heavy metal ions of $\mathrm{Cu} 2+, \mathrm{Cd} 2+$ and $\mathrm{Pb} 2+$ content using AA240DUO atomic adsorption spectrophotometry (Agilent Technologies, Inc. USA). The $\mathrm{pH}$ of solution is determined by a PHS-3C $\mathrm{pH}$

\section{RESULTS AND DISCUSSION}

\section{A. Effect of Adsorbed Dose of Zeolite on Adsorption of Copper, Cadmium and Lead.}

The effects of removal rate of adsorbed dose on the competitive adsorption of $\mathrm{Pb}^{2+}, \mathrm{Cd}^{2+}, \mathrm{Cu}^{2+}$ are shown in Fig.1 when the value of initial concentration of mixed heavy metals is $50 \mathrm{mg} / \mathrm{L}$. The initial value of $\mathrm{pH}$ is 6 , the value of reaction time is 14 hours.

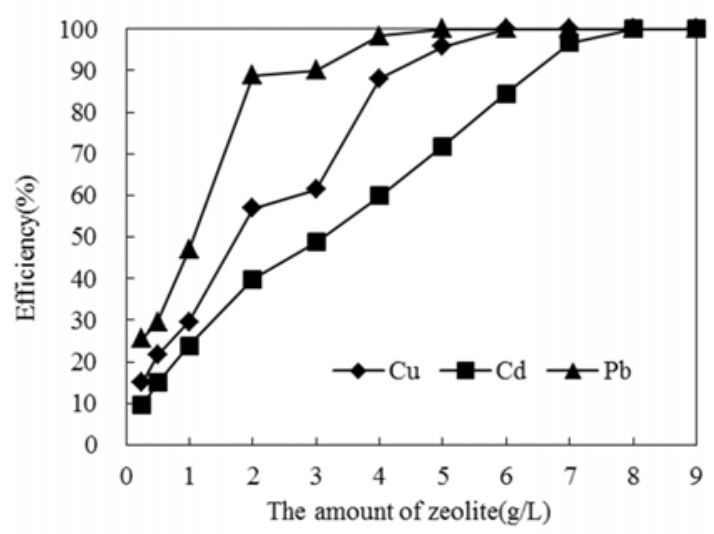

Figure 1. Influence of the amount of zeolite on heavy metal removal rate (the initial metal ionsconcentration $50 \mathrm{mg} \mathrm{L}-1$, contact time $14 \mathrm{~h}, \mathrm{pH}$ value 6.0 , temperature $35^{\circ} \mathrm{C}$ ).

From the Fig. 1 we can know that adsorbed dose has a significant effect on the removal rate of zeolite on the adsorption of $\mathrm{Pb}^{2+}, \mathrm{Cd}^{2+}, \mathrm{Cu}^{2+}$ when the value of initial concentration is $50 \mathrm{mg} / \mathrm{L}$. When the value of adsorbed dose is $0.25 \sim 1 \mathrm{~g} / \mathrm{L}$, the adsorption removal rate of zeolite on $\mathrm{Pb}^{2+}, \mathrm{Cd}^{2+}, \mathrm{Cu}^{2+}$ all have improved to some degree. The adsorption removal rate of zeolite on $\mathrm{Cd}^{2+}$ improves from $9.54 \%$ to $23.90 \%$. The adsorption removal rate of $\mathrm{Cu}^{2+}$ improves from $14.91 \%$ to $29.53 \%$ and the adsorption removal rate of $\mathrm{Pb}^{2+}$ improves from $25.56 \%$ to $46.98 \%$. When the value of adsorbed dose is larger than $2 \mathrm{~g} / \mathrm{L}$, the adsorption removal rate of zeolite on $\mathrm{Pb}^{2+}, \mathrm{Cd}^{2+}, \mathrm{Cu}^{2+}$ all improve significantly. When the value of adsorbed dose is $2 \sim 7 \mathrm{~g} / \mathrm{L}$, the removal rate on $\mathrm{Cd}^{2+}$ improves from $39.92 \%$ to $96.66 \%$, the adsorption tends to be saturated after keeping raising adsorbed dose. When the value of adsorbed dose is $2 \sim 5 \mathrm{~g} / \mathrm{L}$, the removal rate on $\mathrm{Cu}^{2+}$ improves from $56.90 \%$ to $96.01 \%$. When the value of adsorbed dose is $2 \sim 4 \mathrm{~g} / \mathrm{L}$, the removal rate on $\mathrm{Pb}^{2+}$ improves from $88.89 \%$ to $98.25 \%$. When the value of adsorbed dose is larger than $7 \mathrm{~g} / \mathrm{L}$, the rise of adsorbed dose has nothing to do with removal rate, the adsorption system tends to be saturated. We can also see from Fig. 1 that, during the whole adsorption process, competitive adsorption sequence of zeolite on $\mathrm{Pb}^{2+}, \mathrm{Cd}^{2+}, \mathrm{Cu}^{2+}$ is: $\mathrm{Pb}>\mathrm{Cu}>\mathrm{Cd}$. When the heavy metal ions exist together, the adsorption removal rate of zeolite on $\mathrm{Pb}^{2+}$ behaves best. $\mathrm{Cu}^{2+}$ subsequently, and the removal rate of $\mathrm{Cd}^{2+}$ is worst. 


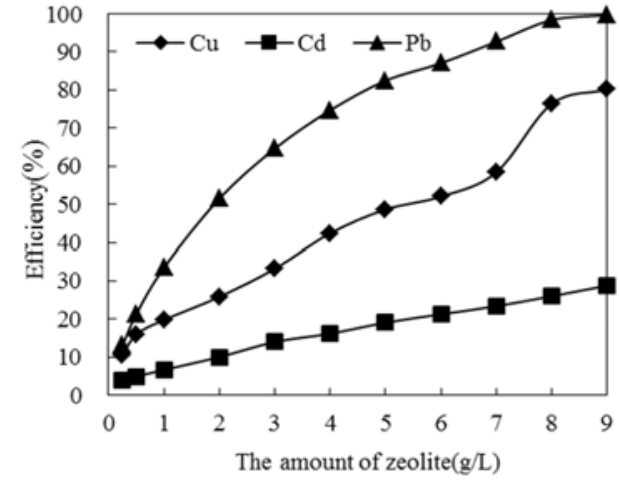

Figure 2. Influence of the amount of zeolite on heavy metal removal rate (initial metal ionsconcentration $100 \mathrm{mg} \mathrm{L}^{-1}$, contact time $14 \mathrm{~h}$, $\mathrm{pH}$ value 6.0 , temperature $35^{\circ} \mathrm{C}$ ).

\section{B. The Effects of Saturated Adsorption Capacity of} Adsorbed Dose of Zeolite on Adsorption of Heavy Metal

When the value of initial concentration is $100 \mathrm{mg} / \mathrm{L}$, the effects of adsorbed dose of competitive adsorption removal rate of zeolite on $\mathrm{Pb}^{2+}, \mathrm{Cd}^{2+}, \mathrm{Cu}^{2+}$ are shown in picture 2 . The adsorbed dose has a significant effect on the removal rate of zeolite on the adsorption of these three heavy metal ions. With the rise of adsorbed dose, the removal rate of zeolite on three heavy metal ions raises constantly, and competitive adsorption sequence of zeolite on the heavy metal ions remains still. When the value of adsorbed dose is $0.25 \sim 1 \mathrm{~g} / \mathrm{L}$, the adsorption removal rate of zeolite on three heavy metal ions all rise to some degree. The removal rate on $\mathrm{Cd}^{2+}$ improves from $3.98 \%$ to $6.69 \%$, the removal rate on $\mathrm{Cu}^{2+}$ improves from $10.58 \%$ to $19.82 \%$, the removal rate on $\mathrm{Pb}^{2+}$ improves from $13.10 \%$ to $33.49 \%$. When the value of adsorbed dose is $2 \sim 9 \mathrm{~g} / \mathrm{L}$, the removal rate of zeolite on three heavy metals rises to various degree. The removal rate on $\mathrm{Cd}^{2+}$ improves from $10.07 \%$ to $28.81 \%$, the removal rate on $\mathrm{Cu}^{2+}$ improves from $25.88 \%$ to $80.15 \%$, the removal rate on $\mathrm{Pb}^{2+}$ improves from $51.51 \%$ to $99.68 \%$.

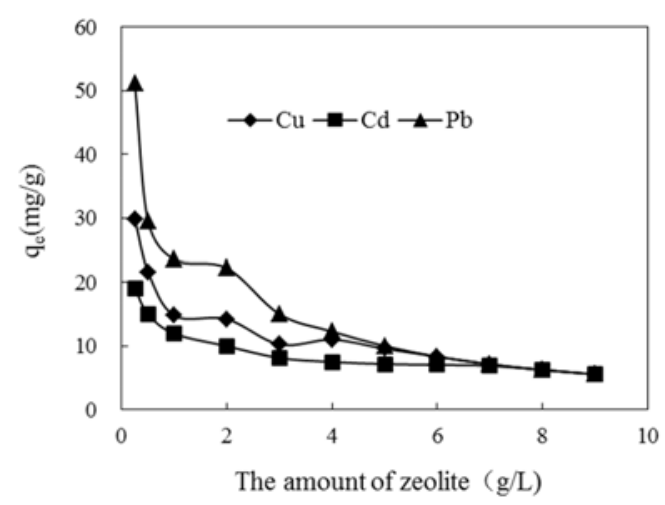

Figure 3. Effect of the amount of zeolite on qe (heavy metal saturated extent of adsorption) (initial metal ionsconcentration $50 \mathrm{mg} \mathrm{L}^{-1}$, contact time $14 \mathrm{~h}, \mathrm{pH}$ value 6.0 , temperature $35^{\circ} \mathrm{C}$ ).

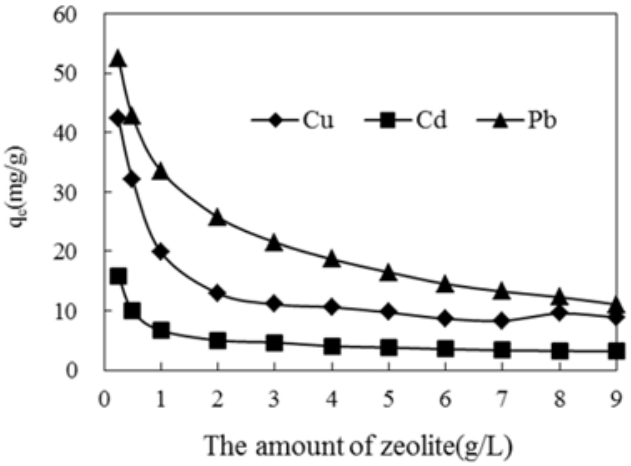

Figure 4. Effect of the amount of zeolite on qe (heavy metal saturated extent of adsorption) (initial metal ionsconcentration $100 \mathrm{mg} \mathrm{L}^{-1}$, contact time $14 \mathrm{~h}, \mathrm{pH}$ value 6.0, temperature $35^{\circ} \mathrm{C}$ ).

The effects of adsorbed dose of saturated adsorption capacity of zeolite on adsorption of $\mathrm{Pb}^{2+}, \mathrm{Cd}^{2+}, \mathrm{Cu}^{2+}$ are shown in picture 3 and picture 4 . With the rise of adsorbed dose, the saturated adsorption capacity on three heavy metal ions keeps getting down, which is that the adsorption capacity of mass fraction adsorbent on the heavy metal ions drops constantly. When the value of adsorbed dose is $0.25 \sim 1 \mathrm{~g} / \mathrm{L}$, the saturated adsorption capacity drops a lot with the rise of adsorbed dose when the value of initial concentration are 50 and $100 \mathrm{mg} / \mathrm{L}$. The adsorption capacity of zeolite on $\mathrm{Cd}^{2+}$ drops from $19.08 \mathrm{mg} / \mathrm{g}$ to $11.95 \mathrm{mg} / \mathrm{g}$ when the value of initial concentration is $50 \mathrm{mg} / \mathrm{L}$ and the value of adsorbed dose is $0.25 \sim 1 \mathrm{~g} / \mathrm{L}$, the adsorption capacity of zeolite on $\mathrm{Cu}^{2+}$ drops from $29.82 \mathrm{mg} / \mathrm{g}$ to $14.77 \mathrm{mg} / \mathrm{g}$, the adsorption capacity of zeolite on $\mathrm{Pb}^{2+}$ drops from $51.11 \mathrm{mg} / \mathrm{g}$ to $23.49 \mathrm{mg} / \mathrm{g}$. The adsorption capacity of zeolite on $\mathrm{Cd}^{2+}$ drops from $15.90 \mathrm{mg} / \mathrm{g}$ to $6.69 \mathrm{mg} / \mathrm{g}$ when the value of initial concentration is $100 \mathrm{mg} / \mathrm{L}$ and the value of adsorbed dose is $0.25 \sim 1 \mathrm{~g} / \mathrm{L}$, the adsorption capacity of zeolite on $\mathrm{Cu}^{2+}$ drops from $42.34 \mathrm{mg} / \mathrm{g}$ to $19.82 \mathrm{mg} / \mathrm{g}$, the adsorption capacity of zeolite on $\mathrm{Pb}^{2+}$ drops from $52.38 \mathrm{mg} / \mathrm{g}$ to $33.49 \mathrm{mg} / \mathrm{g}$. The saturated adsorption capacity of zeolite on three heavy metal ions continues to decrease when the value of adsorbed dose continues to raise. After raising the value of adsorbed dose, the contact area between zeolite and mixed heavy metals in the water increases subsequently so that the utilization ratio of adsorbent reduces as a result.

\section{The Effects of the Value of Initial pH of Zeolite on Adsorption of Copper, Cadmium and Lead}

The effects of the removal rate of the value of initial $\mathrm{pH}$ about the zeolite on the adsorption of heavy metal ions are shown in Fig. 5 when the value of the concentration of heavy metal is $50 \mathrm{mg} / \mathrm{L}$. The value of the adsorbed dose is $4 \mathrm{~g} / \mathrm{L}$, the value of reaction time is 14 hours. As is seen in Fig. 5, the value of $\mathrm{pH}$ has a significant effect on the removal effect of zeolite on the adsorption of three heavy metal ions. With the rise of the value of $\mathrm{pH}$, the removal rate of three heavy metal ions all tend to increase. The competitive adsorption sequence of the zeolite on the heavy metal ions is: 
$\mathrm{Pb}>\mathrm{Cu}>\mathrm{Cd}$. When the value of $\mathrm{pH}$ is 2 , the removal rate of zeolite on $\mathrm{Cd}^{2+}$ is $64.43 \%$; when the value of $\mathrm{pH}$ rises to 4 , the removal rate of zeolite on $\mathrm{Cd}^{2+}$ is $89.32 \%$. When the value of $\mathrm{pH}$ is 6 , the removal rate of zeolite on $\mathrm{Cd}^{2+}$ is $97 \%$, then the process tends to be saturated. When the value of $\mathrm{pH}$ is $2 \sim 4$, the removal rate of zeolite on $\mathrm{Cu}^{2+}$ rises from $77.88 \%$ to $97.20 \%$. When the value of $\mathrm{pH}$ is 2 , the adsorption removal rate of zeolite on $\mathrm{Pb}^{2+}$ arrives at $96.58 \%$. All the evidence indicates that the removal effect of zeolite on $\mathrm{Pb}^{2+}$ is satisfying when three heavy metal ions exist together even if under the acid environment. Besides, it is better than the adsorption removal rate of $\mathrm{Cu}^{2+}$ and $\mathrm{Cd}^{2+}$.

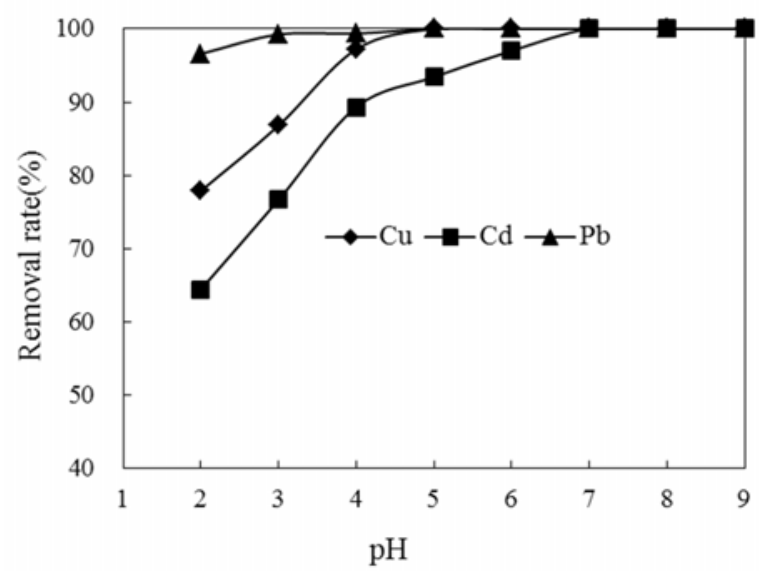

Figure 5. Effect of $\mathrm{pH}$ value on heavy metal efficiency (initial metal ions concentration $50 \mathrm{mg} \mathrm{L}-1$, the value of the adsorbed dose is $4 \mathrm{~g} \mathrm{~L}-1$, contact time $14 \mathrm{~h}$, temperature $35^{\circ} \mathrm{C}$ )

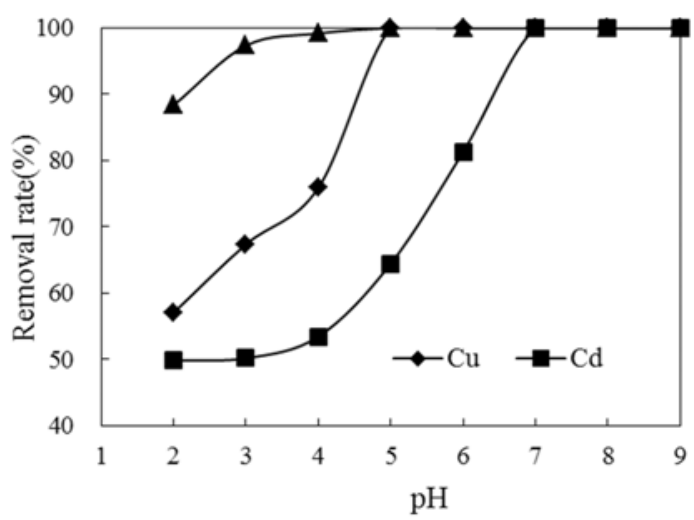

Figure 6. Effect of $\mathrm{pH}$ value on heavy metal efficiency (initial metal ions concentration $100 \mathrm{mg} \mathrm{L}-1$, the value of the adsorbed dose is $4 \mathrm{~g} \mathrm{L-1}$, contact time $14 \mathrm{~h}$, temperature $35^{\circ} \mathrm{C}$ ).

When the value of concentration of mixed ions is $100 \mathrm{mg} / \mathrm{L}$, the effects of the removal rate of the value of initial $\mathrm{pH}$ of zeolite on the adsorption of $\mathrm{Pb}^{2+}, \mathrm{Cd}^{2+}, \mathrm{Cu}^{2+}$ are shown in picture 6 . The value of adsorbed dose is $8 \mathrm{~g} / \mathrm{L}$, the value of reaction time is 14 hours. The removal rate of zeolite on the adsorption of $\mathrm{Pb}^{2+}, \mathrm{Cd}^{2+}, \mathrm{Cu}^{2+}$ rises with the improvement of the value of initial $\mathrm{pH}$ on the whole. The adsorption sequence of zeolite on three heavy metal ions remains still when the value of $\mathrm{pH}$ differs: $\mathrm{Pb}>\mathrm{Cu}>\mathrm{Cd}$. When three heavy metal ions exist together, the removal rate of zeolite on $\mathrm{Pb}^{2+}$ behaves best, $\mathrm{Cu}^{2+}$ subsequently and the removal rate of $\mathrm{Cd}^{2+}$ is worst, which is consistent with the situation when the value of initial concentration is $50 \mathrm{mg} / \mathrm{L}$. When the value of $\mathrm{pH}$ is $2 \sim 6$, the removal rate of zeolite on $\mathrm{Cd}^{2+}$ rises from $49.86 \%$ to $81.34 \%$, then the process tends to be saturated. When the value of $\mathrm{pH}$ is $2 \sim 4$, the removal rate of zeolite on $\mathrm{Cu}^{2+}$ rises from $57.06 \%$ to $75.90 \%$. When the value of $\mathrm{pH}$ is 2, the removal rate of zeolite on $\mathrm{Pb}^{2+}$ is $88.35 \%$; when the value of $\mathrm{pH}$ rises to 3 , the removal rate of zeolite on the adsorption of $\mathrm{Pb}^{2+}$ increases to $97.34 \%$ quickly. As we can see from picture 5 and 6 , when the value of $\mathrm{pH}$ is larger than 6 , the removal rate of zeolite on three heavy metal ions all arrives at $100 \%$. As is speculated, under the circumstance of the value of original $\mathrm{pH}$, there are a lot of hydroxyl ions in the solution and generate precipitated substances with three kinds of heavy metal ions, which affects the process of adsorption reaction.

\section{The Effects of Reaction Time of Zeolite on the Adsorption of Copper, Cadmium And Lead}

The effects of removal rate of reaction time of zeolite on the adsorption of $\mathrm{Pb}^{2+}, \mathrm{Cd}^{2+}, \mathrm{Cu}^{2+}$ are shown in picture 7 (the value of initial concentration is $50 \mathrm{mg} / \mathrm{L}$ ) and picture 8 (the value of initial concentration is $100 \mathrm{mg} / \mathrm{L}$ ).

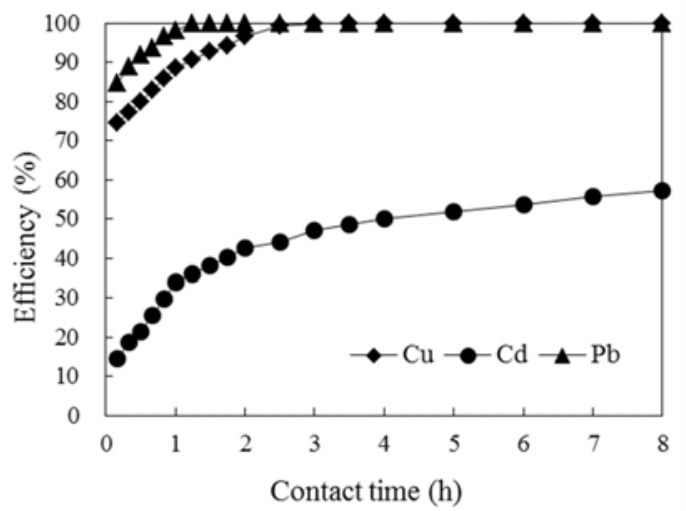

Figure 7. Effect of contact time on heavy metal efficiency (initial metal ions concentration $50 \mathrm{mg} \mathrm{L}-1$; the value of the adsorbed dose is $4 \mathrm{~g} \mathrm{L-1,} \mathrm{pH}$ 6 , temperature $35^{\circ} \mathrm{C}$ ).

As we can see, with the lengthen of reaction time, the removal rate of zeolite on the adsorption of $\mathrm{Pb}^{2+}, \mathrm{Cd}^{2+}, \mathrm{Cu}^{2+}$ rises gradually. During the stage of initial reaction $(0 \sim 2$ hours), the removal rate of synthetic zeolite on the adsorption of $\mathrm{Pb}^{2+}, \mathrm{Cd}^{2+}, \mathrm{Cu}^{2+}$ changes much and improves quickly in this interval. When the value of initial concentration is $50 \mathrm{mg} / \mathrm{L}$, the removal rate of zeolite on $\mathrm{Cd}^{2+}$ increases from $14.56 \%$ to $42.74 \%$; the removal rate of zeolite on $\mathrm{Cu}^{2+}$ increases from $74.58 \%$ to $96.73 \%$; the removal rate of zeolite on $\mathrm{Pb}^{2+}$ is $98.28 \%$ when the value of reaction time is 1 hour. Then the removal rate of zeolite on three heavy metal ions changes little. When the value of initial concentration is $100 \mathrm{mg} / \mathrm{L}$, the 
removal rate of zeolite on $\mathrm{Cd}^{2+}$ increases from $9.93 \%$ at 0.16 hour to $41.98 \%$ at 5 hours to $44.28 \%$ at 8 hours; the removal rate of zeolite on $\mathrm{Cu}^{2+}$ increases from $36.77 \%$ at 0.16 hour to $75.70 \%$ at 5 hours, then the lengthen of time can not improve the removal rate too much; the removal rate of zeolite on $\mathrm{Pb}^{2+}$ increases from $51.61 \%$ at 0.16 hour to $97.85 \%$ at 5 hours and the process tends to be saturated. From the picture 7 and picture 8, we can know that the competitive adsorption sequence of zeolite on three heavy metals remains still with the change of reaction time, which is $\mathrm{Pb}>\mathrm{Cu}>\mathrm{Cd}$.

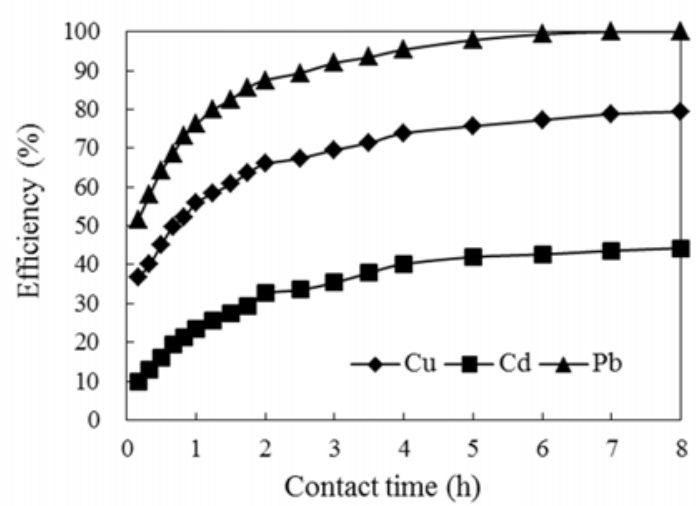

Figure 8. Effect of contact time on heavy metal efficiency (initial metal ions concentration $100 \mathrm{mg} \mathrm{L}-1$; the value of the adsorbed dose is $8 \mathrm{~g} \mathrm{~L}-1$, $\mathrm{pH}$ 6, temperature $35^{\circ} \mathrm{C}$ ).

\section{E. Competitive Adsorption Kinetics.}

For general solid-liquid adsorption process, we usually use Quasi first-class and second-class kinetic equation to conduct kinetic simulation. The quasi first-class kinetic equation is:

$$
\frac{d Q_{t}}{d t}=K_{1}\left(Q_{e}-Q_{t}\right)
$$

$\mathrm{Q}_{\mathrm{t}}$ means the adsorption capacity(mg/g) at the time of $\mathrm{t}$, $\mathrm{Q}_{\mathrm{e}}$ means equilibrium adsorption capacity $(\mathrm{mg} / \mathrm{g})$ of quasi first-class kinetic model, $\mathrm{K}_{1}$ means the adsorption equilibrium speed constant of quasi first-class kinetic model.

Considering the border conditions: Q $\mathrm{t}$ is equal to 0 when $\mathrm{t}=0$; $\mathrm{Q}_{\mathrm{t}}$ is equal to $\mathrm{Q}_{\mathrm{t}}$ when $\mathrm{t}=\mathrm{t}$, we can draw the conclusion by integration:

$$
\log \left(Q_{e}-Q_{t}\right)=\log Q_{e}-\left(K_{1} / 2.303\right) t
$$

The quasi second-class adsorption kinetic equation is:

$$
\frac{d Q_{t}}{d t}=K_{2}\left(Q_{e}-Q_{t}\right)^{2}
$$

The meaning of $Q_{e}$ and $Q_{t}$ is consistent with what is referred in the previous contents, $\mathrm{K}_{2}$ means the adsorption equilibrium speed constantg/(mg. $\mathrm{min})$ of quasi second-class kinetic model. By integration:

$$
t / Q_{t}=1 /\left(K_{2} Q_{e}^{2}\right)+\left(t / Q_{e}\right)
$$

When the value of $t$ is equal to 0 , the initial adsorption speed can be expressed as:

$$
h_{0}=K_{2} Q_{e}^{2}
$$

The equation 4 can be changed to:

$$
t / Q_{t}=1 / h_{0}+t / Q_{e}
$$

Besides, we can judge which kind of first-class kinetic model can be fit for the experimental process by the value of $\mathrm{R}^{2}$ According to RMSE, we can make sure the differences between the adsorption capacity of adsorbents during the experimental process and calculated theoretical adsorption capacity. The smaller the difference of two squares is, the closer the practical adsorption capacity and theoretical adsorption capacity are, which means that the experiment fits kinetic model better. The formula of RMSE is:

$$
R M S E=\sqrt{\sum_{1}^{N}\left(\mathrm{q}_{\exp }-\mathrm{q}_{\mathrm{cal}}\right)^{2} / \mathrm{N}}
$$

In this formula, $\mathrm{q}_{\exp }$ means the practical adsorption capacity in the experimental process, qcalmeans theoretical adsorption capacity of adsorbent, we can calculate and get the results by using the given formula.

\section{F. The Simulation Result When the Initial Concentration of Mixed Heavy Metals is $50 \mathrm{mg} / \mathrm{L}$ and $100 \mathrm{mg} / \mathrm{L}$.}

Conduct the simulation of statistics of zeolite on the adsorption of three heavy metal ions of $\mathrm{Cu}^{2+}, \mathrm{Cd}^{2+}$ and $\mathrm{Pb}^{2+}$ ions by using quasi first-class kinetic equation and quasi second-class kinetic equation, the results are shown in Tab.1. 
TABLE I. THE CONSTANTS AND CORRELATION COEFFICIENTS OF QUASI FIRST-CLASS ANDQUASI SECOND-CLASS KINETIC MODELS FOR ADSORPTION OF HEAVY METAL

\begin{tabular}{|c|c|c|c|c|c|c|c|c|}
\hline \multirow{2}{*}{$\begin{array}{c}\text { Initial } \\
\text { concentration } \\
(\mathrm{mg} / \mathrm{L})\end{array}$} & \multirow[b]{2}{*}{ Metal } & \multirow{2}{*}{$\begin{array}{c}\mathrm{Q}_{\mathrm{e}, \exp } \\
(\mathrm{mg} / \mathrm{g})\end{array}$} & \multicolumn{3}{|c|}{ Pseudo-first-order model } & \multicolumn{3}{|c|}{ Pseudo-second-order model } \\
\hline & & & $\mathrm{Q}_{\mathrm{e}, \mathrm{cal}}(\mathrm{mg} / \mathrm{g})$ & $\mathrm{K}_{1}$ & $\mathrm{R}^{2}$ & $\mathrm{Q}_{\mathrm{e}, \mathrm{cal}}(\mathrm{mg} / \mathrm{g})$ & $\mathrm{K}_{2}$ & $\mathrm{R}^{2}$ \\
\hline & $\mathrm{Pb}^{2+}$ & 12.50 & 3.3602 & 5.8750 & 0.9571 & 12.7226 & 1.7161 & 0.999 \\
\hline & $\mathrm{Cu}^{2+}$ & 12.50 & 5.4157 & 3.2352 & 0.9058 & 12.8205 & 0.5850 & 0.9977 \\
\hline \multirow[t]{6}{*}{50} & $\mathrm{Cd}^{2+}$ & 7.38 & 4.9828 & 0.8351 & 0.9837 & 7.7821 & 0.1435 & 0.9975 \\
\hline & & RMSE & 9.1398 & & & 0.2226 & & \\
\hline & & & 7.0843 & & & 0.3205 & & \\
\hline & & & 2.3972 & & & 0.4021 & & \\
\hline & $\mathrm{Pb}^{2+}$ & 12.50 & 6.2959 & 1.5142 & 0.9803 & 12.9198 & 0.2359 & 0.9988 \\
\hline & $\mathrm{Cu}^{2+}$ & 10.20 & 4.9342 & 0.8721 & 0.9873 & 10.3950 & 0.2034 & 0.9984 \\
\hline \multirow[t]{4}{*}{100} & $\mathrm{Cd}^{2+}$ & 5.78 & 4.1954 & 0.8684 & 0.9869 & 6.2617 & 0.1476 & 0.9967 \\
\hline & & RMSE & 6.2041 & & & 0.4198 & & \\
\hline & & & 5.2658 & & & 0.1950 & & \\
\hline & & & 1.5846 & & & 0.4817 & & \\
\hline
\end{tabular}

From Tab.1, according to quasi first-class and quasi second-class kinetic calculation results, the value of quasi first-class kinetic simulation correlation coefficient R2 are $0.9571,0.9058,0.9837$ respectively when the value of initial concentration is $50 \mathrm{mg} / \mathrm{L}$, the value of quasi second-class kinetic simulation correlation coefficient R2 are 0.999,0.9977,0.9975(all larger than 0.99) respectively. Compared to the value of RMSE, the value of quasi second-class kinetic RMSE of three heavy metal ions $(0.2226,0.3205,0.4021)$ are smaller than the value of quasi first-class kinetic RMSE(9.1398,7.0843,2.3972), which means that the value of quasi second-class kinetic equilibrium adsorption capacity $\mathrm{Q}_{\mathrm{cal}}$ is closer to the value of experimental measurement $\mathrm{Q}_{\text {exp. }}$

When the value of initial concentration is $100 \mathrm{mg} / \mathrm{L}$, the value of quasi first-class kinetic simulation correlation coefficient of three heavy metal ions $\mathrm{R}^{2}$ are $0.9803,0.9873,0.9869$ respectively, the value of quasi second-class kinetic simulation correlation coefficient of three heavy metal ions $\mathrm{R}^{2}$ are 0.9988,0.9984,0.9967 respectively, which means that the value of quasi second-class kinetic simulation correlation coefficient are larger than the value of quasi first-class kinetic simulation correlation coefficient. Compared to the value of RMSE, the value of quasi second-class kinetic RMSE of three heavy metal ions $(0.4198,0.1950,0.4817)$ are smaller than the value of quasi first-class kinetic RMSE (6.2041, 5.2658,
1.5846). As we can see, the simulation degree of quasi first-class adsorption kinetics of zeolite on the adsorption of three heavy metal ions is terrible, the simulation degree of quasi second-class adsorption kinetics is just the opposite. When the value of initial concentration of mixed heavy metal ions are $50 \mathrm{mg} / \mathrm{L}$ and $100 \mathrm{mg} / \mathrm{L}$ respectively, the adsorption behavior of zeolite on the adsorption of three heavy metal ions all fits for quasi second-class adsorption kinetic equation.

\section{CONCLUSIONS}

The adsorbed dose both has the significant effect on the removal rate and saturated adsorption capacity of zeolite on the adsorption of three heavy metal ions. With the increase of adsorbed dose, the removal rate of zeolite on the adsorption of three heavy metals all rise constantly. When the value of initial concentrations are 50 and $100 \mathrm{mg} / \mathrm{L}$, the competitive adsorption sequence of zeolite on three heavy metal ions is: $\mathrm{Pb}>\mathrm{Cu}>\mathrm{Cd}$. With the increase of adsorbed dose, the saturated adsorption capacity of zeolite on heavy metal ions all drops constantly, which is that adsorption capacity of the mass fraction zeolite adsorbent on three heavy metal ions decreases constantly. When the value of adsorbed dose is $0.25 \mathrm{~g} / \mathrm{L} \sim 1 \mathrm{~g} / \mathrm{L}$, the saturated adsorption capacity in the adsorption system whose initial concentration are $50 \mathrm{mg} / \mathrm{L}$ and $100 \mathrm{mg} / \mathrm{L}$ both drops a lot with the increase of adsorbed dose. 
When the value of initial concentration are $50 \mathrm{mg} / \mathrm{L}$ and $100 \mathrm{mg} / \mathrm{L}$, the removal rate of zeolite on the adsorption of three heavy metal ions all increases with the rise of the value of initial $\mathrm{pH}$ on the whole. During the competitive adsorption process, at various value of initial $\mathrm{pH}$ and concentration, the adsorption sequence of zeolite on three heavy metals remains still: $\mathrm{Pb}>\mathrm{Cu}>\mathrm{Cd}$. When the value of initial $\mathrm{pH}$ is larger than 6 , the hydroxyl ions of adsorption system and three heavy metal ions both generate precipitation substances so that the process of adsorption reaction is affected.

The reaction time has apparent effect on the removal rate of zeolite on the adsorption of three heavy metal ions. The removal rate of zeolite increases gradually with the lengthen of reaction time. The adsorption removal rate of zeolite on the adsorption of three heavy metal ions improves quickly within 2 hours. With the change of reaction time, competitive adsorption sequence of zeolite on three heavy metals keeps still.

When the value of initial concentration of mixed heavy metal ions are $50 \mathrm{mg} / \mathrm{L}$ and $100 \mathrm{mg} / \mathrm{L}$ respectively, the value of quasi first-class kinetic simulation correlation coefficient of three heavy metal ions R2 are smaller than the value of quasi second-class kinetic simulation correlation coefficient R2 . Besides, compared to the value of RMSE, the value of quasi second-class kinetic equation RMSE are all smaller than the value of quasi first-class kinetic equation RMSE under different value of initial concentration, which means that the value of equilibrium adsorption capacity of quasi second-class kinetic equation $Q_{\exp }$ is closer to the value of equilibrium adsorption capacity $\mathrm{Q}_{\text {cal }}$ according to experimental measurement. The adsorption behavior of synthetic zeolite materials on the adsorption of three heavy metal ions all fits for quasi second-class adsorption kinetic equation.

\section{ACKNOWLEDGMENT}

This work was financial supported by the Natural Science Foundation of China (NSFC) (Grant No. 21407068), Science Foundation of Jiangsu Colleges and Universities (Project No. 09KJB610004), 2016 University of Jiangsu Province Blue Project of young academic leader training objects, Open Fund Project of Jiangsu Provincial Key Laboratory of Environmental Engineering (Grant No. KF2014002, KF2015011), “13th Five-Year Plan” key subject of Jiangsu City Vocational College (Grant No. 16SSW-Z-001).

\section{REFERENCES}

[1] F. Boudrahem, F. Aissani-Benissad and H. Ait-Amar, J. Environ. Manage.90, 3031 (2009).

[2] S. Noppadol and P. Pongsakorn, Pol. J. Environ. Stud.23,853 (2014).

[3] C. Chen, T. Cheng and Y. S. Shi, Iran. J. Chem. Chem. Eng.33,29 (2014).

[4] T. M. Alslaibi, I. Abustan and M. A. Ahmad, J. Environ. Chem. Eng. 1, 589(2013).

[5] A. Papandreou, C. J. Stournaras and D. Panias, J. Hazard. Mater.148,538 (2007).

[6] S. H. Yao, X. X. Jiang and D. K. Shen, Journal of Southeast University (Natural Science Edition)45, 515(2015). (in Chinese)

[7] C. Chen, T. Cheng and Z. L. Wang, J. Indian Chem. Soc.91,1 (2014).

[8] A. Z. Kamel, S. A. Mohammad and B. H. Falah,J. Hazard. Mater. 188,414 (2011).

[9] M. Ahmaruzzaman,Prog. Energy Combust. Sci.36,327 (2010).

[10] K. S. Hui, C. Y. H. Chao and S.C. Kot, J. Hazard. Mater.B127,89 (2005). 